BLS 33, No 1 2007. DOI: http://dx.doi.org/10.3765/bls.v33i1.3515

(published by the Berkeley Linguistics Society and the Linguistic Society of America)

\title{
VP Ellipsis in Japanese ${ }^{1}$
}

\author{
MICHIKO TODOKORO BUCHANAN \\ University of Minnesota
}

\section{Introduction}

This study examines the Japanese phenomenon where VP is not overtly expressed but recoverable, as exemplified in (1), where (1b) and (1c) are preceded by (1a). Although the property of this phenomenon is shared with English VP ellipsis (VPE), it has not been discussed in detail to date.

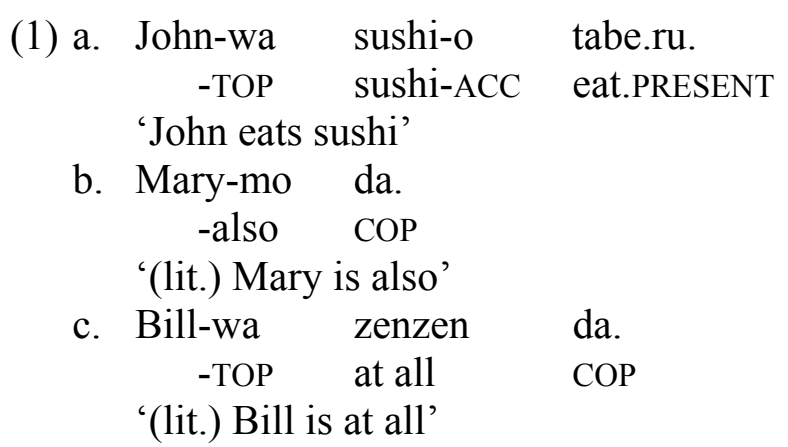

In (1b) and (1c), there is no VP, and the copula da appears. For (1b), it is interpreted as 'Mary does too'. For (1c), despite the fact that there is no negation marker, it reads 'Bill doesn't at all.' Since Japanese verb morphology is different from English, there is no parallel structure to English VPE. However, (1b) and (1c) exhibit some parallelism to the English counterpart. That is, as long as there is a linguistic antecedent, redundant VPs can be elided and the elided VPs are recoverable.

I consider this Japanese phenomenon to be a type of VPE (referred to as Japanese VPE hereinafter), and investigate how the copula $d a$ appears; what allows the ellipsis to occur (Licensing Condition); and how the elided VP is recovered

\footnotetext{
${ }^{1}$ I am grateful for the help and encouragement from Jeanette Gundel, Hooi Ling Soh, Amy Sheldon, and Nancy Stenson. A part of this study was presented at the Workshop of Negation and Polarity held at the University of Tübingen in March 8-10, 2007. I would like to thank the audiences at the workshop for their comments. Thanks are also due to the audiences at BLS 33 .
} 
(Identity Condition). I argue that elements that can determine the negation of the clause can license ellipsis, and that ellipsis is allowed under the syntactic identity. To account for the appearance of the copula $d a$, I claim that No-da 'It's that' Focus Construction is the underlying construction for the Japanese VPE, and that the VPE undergoes focus movement and remnant deletion. This analysis assumes the presence of a syntactic structure that holds the moved focused element. Thus, this study contributes to cross-linguistic analyses of Rizzi's (1997) structure of the left periphery, as well as to cross-linguistic studies of VPE.

\section{Japanese VPE: Previous Studies}

Because of its different verb morphology, Japanese does not have VPE parallel to English VPE. Japanese lacks $d o$-support, and its tense morphemes are bound to the verb. Japanese VPE parallel to the English VPE in (2), therefore, is ungrammatical, as shown in (3).

(2) a. John eats sushi.

b. Mary does $[e]$ too.

(3) a. John-wa sushi-o

$$
\text { -TOP -ACC eat.PRESENT }
$$

'John eats sushi'

b.* Mary-mo [e]-ru.

-also -PRESENT

'[intended reading] Mary does too'

In English, not can precede an ellipsis site as in (4b). However, the Japanese negation morpheme is bound to the verb, therefore, the Japanese counterpart to (4b) is ungrammatical, as seen in (5b).

(4) a. John eats sushi.

b. Mary does not $[e]$.

(5) a. John-wa sushi-o

tabe.ru.

-TOP -ACC eat.PESENT

'John eats sushi'

$\begin{array}{cc}\text { b.* Mary-wa } & {[e] \text {-nai. }} \\ \text {-TOP } & \text {-NEG.PRESENT } \\ \text { '[intended reading] Mary does not' }\end{array}$

There is an approach that claims VPE occurs in Japanese. Otani and Whitman (1991) claim that the null object construction in Japanese is VPE assuming the Vto-T raising. They argue that the availability of a sloppy reading in the null object constructions like (6) is evidence for Japanese VPE, since, as noted by Sag (1976) and Williams (1977), a sloppy reading is available in English VPE as in (7). 


\section{VPE in Japanese}

(6) a. John-wa [zibun-no tegami-o] sute-ta. John-NOM self-of letter-ACC discard-PERF

'John ${ }_{i}$ threw out self $i$ 's letters'

b. Mary-mo

[e]

sute-ta.

Mary-also

discard-PERF

$=$ Mary $_{j}$ also threw out self ${ }_{j}$ 's letters. (sloppy reading)

$=$ Mary also threw out John's letters. (strict reading)

(Otani and Whitman 1991:346-347)

(7) John likes his children, and Bill does too.

$=\mathrm{John}_{i}$ likes his $_{i}$ children, and Bill ${ }_{j}$ likes his $_{j}$ children. (sloppy reading)

$=\mathrm{John}_{i}$ likes his $_{i}$ children, and Bill likes John's children. (strict reading)

(Williams 1977:118)

After Otani and Whitman's argument that the null object construction is VPE in disguise in Japanese, Hoji (1998), Oku (1998), and Tomioka (1998) argue against the VPE analysis of the sloppy reading in the null object construction. Hoji argues that the null object is pro, and the null argument is pragmatically recovered. Oku points out that the sloppy identity reading is also available for null subjects in Japanese, and argues that VPE is not necessarily responsible for the sloppy readings. Tomioka argues that pro is sometimes a pronoun of "laziness". "Laziness" is used to describe a property of pronouns that allows them to refer to a closely preceding referent as illustrated in (8) below.

(8) A man $w_{1} o_{1}$ gives his 1 paycheck to his wife is wiser than a man $w^{2} o_{2}$ gives it $\left(\neq\right.$ his $_{1}$ paycheck, $=$ his $_{2}$ paycheck $)$ to his cat.

These arguments are concerned with the source of the sloppy reading in Japanese. The sloppy reading is used as strong evidence for Otani and Whitman's claim that the Japanese null object construction is VPE in disguise. Therefore, the arguments against the source of the sloppy reading leads to the argument against the VPE analysis of the null object construction. In the current study, I discuss Japanese VPE setting the sloppy reading aside.

\section{Japanese VPE in This Study}

In (1b) and (1c), which I claim as Japanese VPE, the copula da appears. In standard Japanese, the copula is always preceded by nominals, and VP cannot be immediately followed by the copula, as seen in (9).

$$
\begin{array}{rrll}
* \text { Mary-ga } & \text { sushi-o } & \text { taberu } & \text { da. } \\
\text {-NOM } & - \text { ACC } & \text { eat } & \text { COP }
\end{array}
$$

In order to account for the appearance of the copula, inspired by Hiraiwa and Ishihara's (2002) analysis of Japanese Sluicing, I claim that No-da 'It's that' Focus Construction is the underlying construction for Japanese VPE. In No-da 
Focus Construction, the entire main clause is nominalized by the nominalizer no and the copula $d a$ follows, as seen in (10).

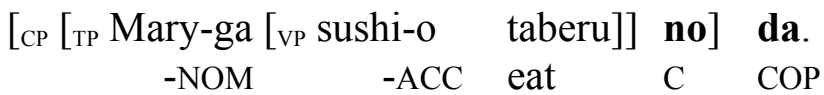

$$
\begin{aligned}
& \text { 'It's that Mary eats sushi' }
\end{aligned}
$$

The whole nominalized clause is focused in this construction. Thus, in (10), the entire clause, Mary-ga sushi-o taberu 'Mary eats sushi', is focused.

Also, adopting Rizzi's (1997) structure of the left periphery, I propose that topics and focused elements can move out to the left periphery CP-domain from the underlying No-da Focus Construction in order for a focused element to be more prominent. Rizzi's thought of the structure of the left periphery, that is, the complementizer system, is illustrated in $(11)^{2}$. I argue that, in Japanese, topics and the prominent focused items overtly move to Spec of TopP and Spec of FocP, respectively. Rizzi describes the complementizer system as the interface between a propositional content and a higher structure, such as, a higher clause or discourse articulation. Since VPE does not occur without discourse context, specifically, linguistic antecedents, the idea of the $\mathrm{CP}$-domain as discourse articulation fits the structure of VPE.

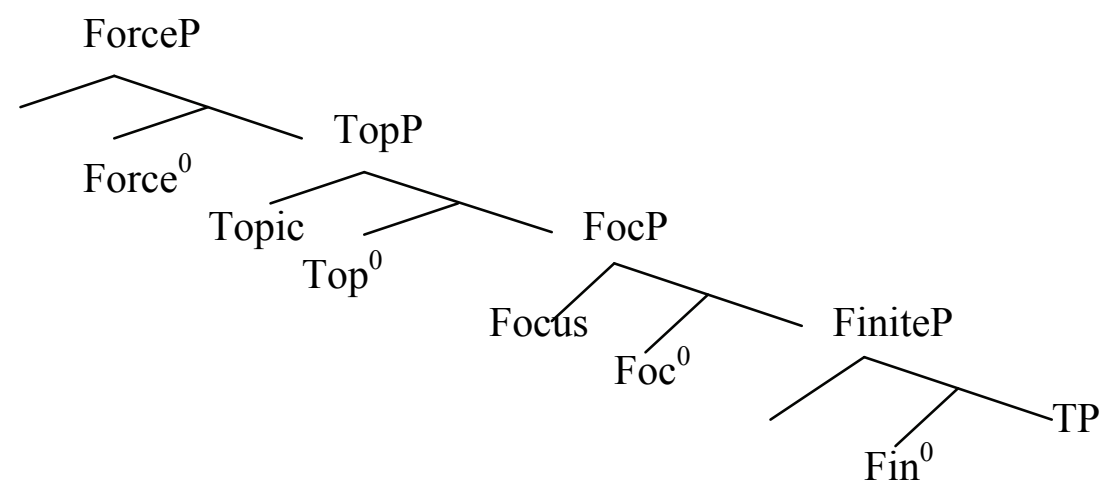

Considering No-da Focus Construction and the left periphery structure, the underlying constructions and the derivation for (1b) and (1c) are (12b) and (12c), respectively.

\footnotetext{
${ }^{2}$ According to Rizzi, the complement of $\operatorname{Top}^{0}$ is the comment, that is, new information, and the complement of $\mathrm{Foc}^{0}$ is the presupposition, that is, given information. Rizzi, therefore, assumes that TopP can be recursive, while FocP cannot. In this paper, however, only overtly expressed TopP appears in the diagram.
} 


\section{VPE in Japanese}

(12)a. John-wa sushi-o tabe.ru.

-TOP -ACC eat.PRESENT

b. Mary-mo ${ }_{i}\left[{ }_{P}\left[{ }_{T P} t_{i}\left[{ }_{* P}-\right.\right.\right.$ sushi- $\theta$ tabe.ru $\left.]\right]$ nø] da. -also -ACC eat.PRESENT C COP

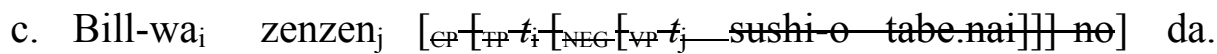
-TOP at all -ACC eat.NEG $\mathrm{C}$ COP

The tree diagram (13) schematically illustrates the derivation of $(12 b)^{3}$. The operation is structurally CP ellipsis. However, the motivation of the ellipsis is to elide a redundant VP, thus, I refer to this phenomenon as VP ellipsis in this study.

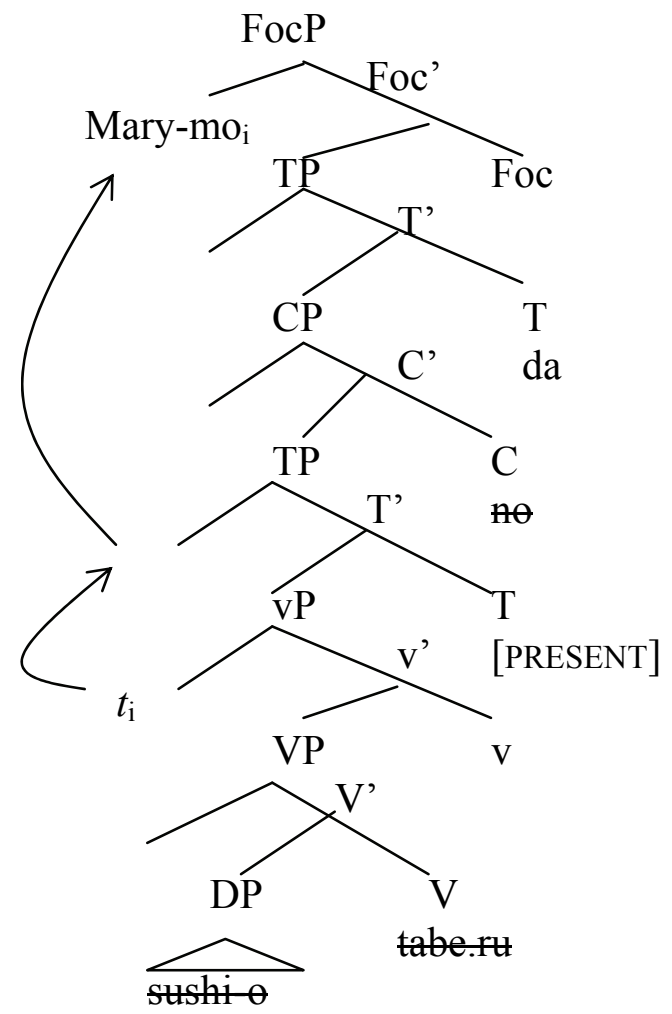

Kim and Sohn (1998) discuss a Korean structure similar to (1b) in relation to VPE. They refer to these structures in Korean and Japanese as Pseudo-VPE. The Korean Pseudo-VPE is illustrated in (14).

\footnotetext{
${ }^{3}$ Hiraiwa and Ishihara claim that the copula $d a$ is the head of FocP. However, in this study, since the copula carries tense, I assume that there is a TP layer where the copula is generated between the $\mathrm{CP}$ and the FocP.
} 
Michiko Todokoro Buchanan

$\begin{array}{clllrll}\text { John-i } & \text { sakwa-lul } & \text { meke } & \text { (kuliko) } & \text { MARY-to } & {[\mathrm{e}]} & \text { ya. } \\ \text {-Nom } & \text { apple-Acc } & \text { eats } & \text { and } & - \text { Foc } & & \text { is }\end{array}$

'John eats apples, and MARY does too'

(Kim and Sohn 1998:460)

They claim, within a minimalist framework, that the focused item with the strong [+focus] feature moves to Spec of FocP to check its [+focus] feature. In their analysis, they argue that the copula $y a$ in Korean and $d a$ in Japanese support the stranded tense after the remnant deletion occurs. However, in Japanese VPE, the tense of the copula and the tense of the elided VP can be different, as seen in (15b).

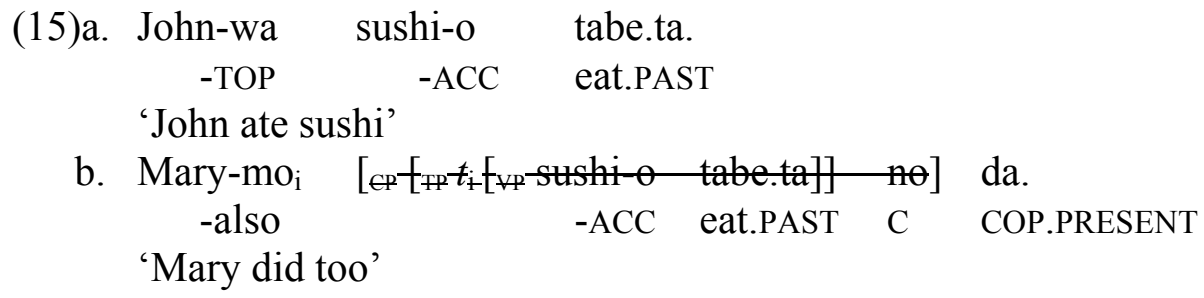

In (15), the tense of the antecedent VP in (15a) and the tense of the elided VP in (15b) are PAST, while the tense of the copula in (15b) is PRESENT. This shows that the copula in the Japanese VPE does not play the role as Kim and Sohn claim.

\section{Licensing Conditions and Identity Conditions}

Studies on English VPE have been discussing two issues extensively; the licensing conditions - that is, under what condition ellipsis can occur - and the identity conditions - that is, how the missing items are recovered. Among the widely accepted elements that can license English VPE are: the morphologically realized head, such as, auxiliaries, including modals, have, be, and do (Bresnan 1976), $\mathrm{X}^{0}$ specified for strong agreement (Lobeck 1995), and $\mathrm{Neg}^{0}$ (Potsdam 1997).

The debate on the identity conditions has been between proponents of syntactic analysis and semantic analysis. The syntactic analysis claims that ellipsis involves syntactic representation at some point, either at PF or LF. There are two approaches in the syntactic analysis: PF-deletion approach and LF-reconstruction approach. The PF-deletion approach claims that the ellipsis site has a syntactic structure, but it is not overtly pronounced (Tancredi 1992, Fox 2000, among others). LF-reconstruction approach claims that the ellipsis site does not have syntactic structure, but it involves syntactic recovery at LF (Williams 1977, Fiengo and May 1994, among others). On the other hand, the semantic analysis argues that the elided site does not have syntactic representation at all, either at PF or LF (Dalrymple, Shieber and Pereira 1991, Hardt 1999, among others).

In what follows, I examine the licensing conditions (Section 3.1) and the identity conditions (Section 3.2) for Japanese VPE. 


\section{VPE in Japanese}

\subsection{Licensing Conditions for Japanese VPE}

I claim that items that can determine the negation of the clause can license Japanese VPE. For example, -mo 'also' can determine the negation in relation to the preceding sentence. Zenzen '(not) at all' determines the negation of the clause regardless of the negation of the preceding sentence. Thus, both can precede an ellipsis site.

\subsubsection{Licensor -mo 'also': [ $\alpha$ neg]}

According to the negation of the preceding sentence, -mo 'also' can determine the negation of the clause. That is, if the preceding sentence is positive, the sentence that contains - $m o$ is also positive, as seen in (16).

$\begin{array}{cll}\text { (16)a. John-wa sushi-o } & \text { tabe.ru. } \\ \text {-TOP } & \text {-ACC } & \text { eat.PRESENT } \\ \text { 'John eats sushi' } & \\ \text { b. Meg] } & \\ \text { b. Mary-mo sushi-o } & \text { tabe.ru. } \\ \text {-also -ACC eat.PRESENT } & \text { 'Mary eats sushi too' }\end{array}$

If the preceding sentence is negative, the sentence that contains -mo is also negative, as seen in (17).
a. John-wa sushi-o -TOP $\quad-A C C$

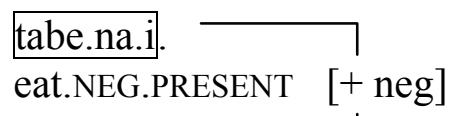 'John doesn't eat sushi'
b. Mary-mo sushi-o -also $\quad-\mathrm{ACC}$ 'Mary doesn't either'
tabe.na.i.
eat.NEG.PRESENT

The negation of the clause that contains - $m o$ is the same as the one in the previous sentence. Thus, I claim that $[\alpha$ neg] is encoded in $-m o$.

Since - $m o$ can determine the negation, which is $[\alpha$ neg] in relation to the previous sentence, the negation of the ellipsis site preceded by -mo is recoverable. This is illustrated in (18) and (19). (18) is same as (1b).
(18)a. John-wa
sushi-o
tabe.ru.
'John eats sushi' [- neg]
-TOP
$-\mathrm{ACC}$
eat.PRESENT
b. Mary-mo da. -also COP
(19)a. John-wa sushi-o
-top -ACC
b. Mary-mo da.
eat.NEG.PRESENT
'Mary does too' [- neg] -also COP
'Mary doesn't either' [+ neg] 


\section{Michiko Todokoro Buchanan}

The Japanese VPE licensor -mo is commonly referred to as a focus marker. Focus markers make elements followed by them prominent. I have been claiming in this paper that focused items can move up to Spec of FocP in the complementizer system, and the remnant can be elided under certain conditions. Therefore, focus markers may seem to be the key to license Japanese VPE. However, the VPE licensing of $-m o$ is solely attributed to [ $\alpha$ neg] encoded in -mo. I demonstrate that not all focus markers can license Japanese VPE in Section 3.1.3.

\subsubsection{Licensor zenzen '(not) at all': [+neg]}

Zenzen '(not) at all' is a Japanese adverbial expression that denotes frequency or quantity, and it is a Negative Polarity Item (NPI) in that it must appear with negation ${ }^{4}$, as seen in (20).

$$
\begin{array}{ccccc}
\text { John-wa } & \text { zenzen } & \text { sushi-o } & \{\text { tabe.nai } / * \text { taberu } \\
\text {-TOP } & \text { at all } & \text {-ACC } & \text { eat.NEG eat }
\end{array}
$$

'John $\{$ doesn't eat sushi / *eats sushi $\}$ at all.'

I observe that this NPI can license Japanese VPE, as seen in (1c), repeated as (21b) here.

$$
\begin{array}{rrl}
\text { (21)a. John-wa } & \text { sushi-o } & \text { tabe.ru. } \\
\text {-TOP } & \text {-ACC } & \text { eat.PRESENT }
\end{array}
$$

'John eats sushi'

$\begin{array}{rrr}\text { b. Bill-wa } & \text { zenzen } & \text { da. } \\ \text {-TOP } & \text { at all } & \text { COP }\end{array}$

'Bill doesn't at all'

I claim that $[+$ neg] is encoded in zenzen, which allows it to license ellipsis. That is, regardless of the negation of the preceding sentence, the ellipsis site preceded by zenzen is interpreted as negative.

I note that not all NPIs can license Japanese VPE, as seen in (22). The adverbial expressions in the curly parentheses are NPIs, as shown in (23).

(22)a. John-wa sushi-o taberu.

-TOP -ACC eat

b. Mary-wa \{zenzen/ mattaku/ sappari/*kessite/*sukosi-mo/*amari\} da.

-TOP at all at all at all at all a bit-even much COP

(23) Mary-wa \{zenzen / mattaku / sappari / kessite / sukosi-mo / amari\} sushi-o $\quad$ tabe.nai $/ *$ taberu\}.

'Mary \{doesn't eat sushi / *eats sushi $\}$ \{at all / at all /at all /at all/ even a bit / much\}'

\footnotetext{
${ }^{4}$ When zenzen is used with adjectives to denote degree, it sometimes appears with affirmation. This study, however, focuses on the use of zenzen with verbs, where it must appear with negation.
} 


\section{VPE in Japanese}

My claim is as follows. NPIs that can license ellipsis, such as, zenzen 'at all', mattaku 'at all', and sappari 'at all', are [+ neg]. With them, negation is emphasized because of their $[+$ neg]. Kessite 'at all' also emphasizes negation. However, unlike NPIs with $[+$ neg], it expresses the person's strong determination. The negation is emphasized by the depiction of how strong the person's determination is, not by [+ neg]. Sukosi-mo 'even a bit' also emphasizes negation. It is a minimizer that denotes a minimal quantity. With sukosi-mo in (23), that Mary does not eat even a minimal quantity of sushi is expressed. That is, the emphasis is inferred semantically/pragmatically. Amari 'much', which is an attenuating NPI in Israel's (2001) term, makes the negative statement weaker, thus, we can assume that it is not semantically negative.

\subsubsection{Focus Markers That Cannot License Japanese VPE}

A focus marker - $m o$ can license Japanese VPE, but not all focus markers license ellipsis, as seen in (24).

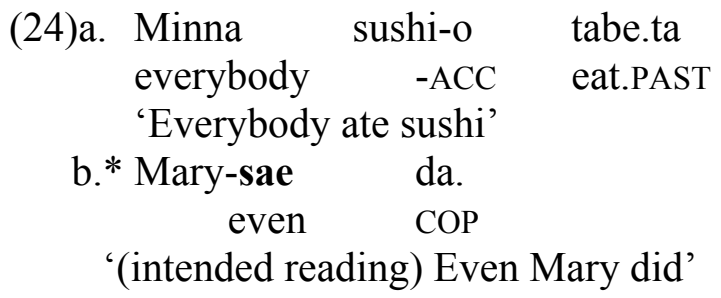

Since -sae 'even' cannot determine the negation of the clause, it cannot license ellipsis. This indicates that being focused is not the key; rather, being able to determine the negation is the key to the Japanese VPE.

There is other evidence for the significance of the negation. The Japanese topic marker - wa is referred to as a contrast marker in a certain context (Kuno 1973). Elements followed by -wa contrast with elements in the preceding sentence, which results in making the element with -wa prominent. Thus, it is also referred to as a focus marker. The use of the contrast marker -wa is illustrated in (25).

$$
\begin{array}{rll}
\text { (25)a. } & \text { John-wa sushi-o } & \text { taberu. } \\
- \text { TOP } & \text { ACC } & \text { eat } \\
& \text { 'John eats sushi' } \\
\text { b. } & \text { Mary-wa sushi-o tabe.nai. } \\
& \text {-CONTRAST -ACC eat.NEG } \\
& \text { '(In contrast,) Mary doesn't eat sushi.' }
\end{array}
$$

-CONTRAST -ACC eat.NEG

In (25), the contrast in negation occurs, that is, (25a) is affirmative while (25b) is negative. This results in the appearance of the contrast marker -wa. However, the contrast is not always between negation and affirmation. Thus, -wa does not always predict the negation of the clause. This is illustrated in (26). 


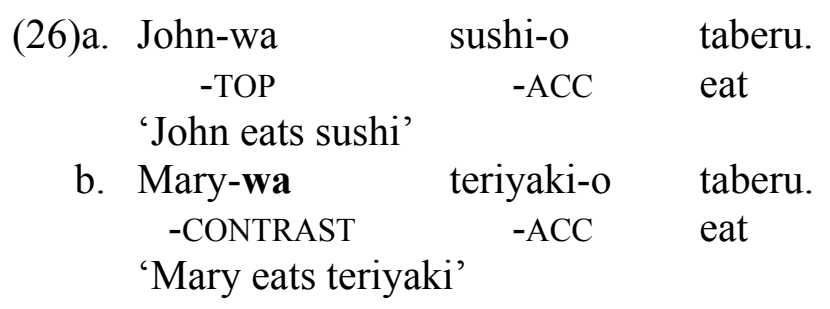

In (26), the contrast is between what they eat, but not in negation. This indicates that $-w a$ cannot determine the negation of the clause. For this reason, -wa cannot license Japanese VPE, as seen in (27), which is intended to be the ellipsis counterpart of (25).

(27)a. John-wa sushi-o taberu. -TOP -ACC eat

'John eats sushi'

$$
\begin{array}{ll}
\text { b.* Mary-wa } & \text { da. } \\
\text {-CONTRAST } & \text { COP } \\
\text { (intended reading) Mary doesn't' } &
\end{array}
$$

These ungrammatical examples seen above indicate that being focused or contrasted is not the primary key to licensing Japanese VPE. Instead, whether or not the element can determine the negation of the clause is the key. They also show that the copula $d a$ is not solely responsible for Japanese VPE.

\subsection{Identity Conditions}

In this study, I claim that Japanese VPE is a consequence of PF-deletion, and it is allowed under syntactic identity. In what follows, evidence for PF-deletion is provided. I also discuss how VPs are deleted and recovered in Japanese VPE.

\subsubsection{PF-deletion under Syntactic Identity}

Assuming NPIs are licensed at a syntactic level, I argue that the fact that zenzen is overtly expressed is the indication of the appearance of the negation marker at PF. That leads to my claim that Japanese VPE is considered to be a result of PFdeletion.

Additional evidence for the PF-deletion analysis is as follows. I observe that Japanese VPE is not allowed without linguistic antecedent, as seen in (28).

(28) [Seeing John is eating sushi...]

\# Watashi-mo da.

I-also COP.PRESENT

'[intended reading] I'm going to eat sushi too' 


\section{VPE in Japanese}

In Hankamer and Sag's (1976) work on what controls anaphora, they discuss two types of anaphora; Surface Anaphora, which is syntactic controlled anaphora, and Deep Anaphora, which is pragmatic controlled anaphora. Surface Anaphora requires a linguistic antecedent, while the meaning of Deep Anaphora can be recovered pragmatically. According to their classification, Japanese VPE is Surface Anaphora: it requires a linguistic antecedent. Following their claim that Surface Anaphora involves syntactic deletion, I argue that Japanese VPE involves syntactic deletion. English VPE also exhibits the same property (Hankamer and Sag 1976).

\subsubsection{Deletion and Recovery}

In this section, I demonstrate how the deletion of VP occurs, and how the elided VP is recovered taking ellipsis involving zenzen as an example. I argue that in a sentence where a semantically negative NPI (e.g., zenzen) appears, the negation marker -nai is always a candidate for deletion because of the semantic redundancy of $[+$ neg]. However, since $-n a i$ is bound to the verb in Japanese, it cannot be elided leaving VP as shown in (29).

$$
\text { * Mary-wa zenzen sushi-o tabe-[e]. (e=nai) }
$$

Thus, for ellipsis like (1c) to occur, two conditions have to be satisfied: there is a linguistic antecedent; the NPI is semantically negative. This is illustrated in (30).

(30)a. John-wa

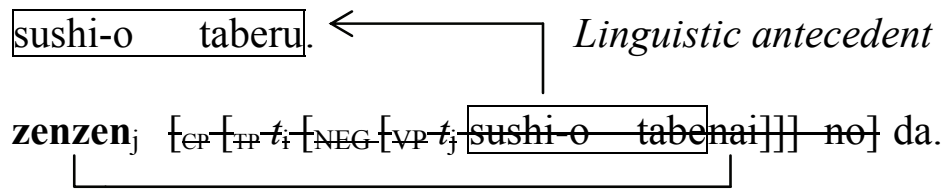

b. Mary-wa

Semantic redundancy of negation

Following Rooth (1992), I consider ellipsis to be a device expressing redundancy. Recovery of the elided VP in (30b) works as follows. Ellipsis followed by the copula $d a$ indicates that there are syntactic and/or semantic redundancies. The VP, sushi-o taberu 'eat sushi', is available from the preceding clause in (30a), and zenzen, where $[+$ neg] is encoded, adds the negation to the VP. Thus, Mary doesn't eat sushi is recovered.

\section{Summary}

This study examined the Japanese phenomenon where VPs are not overtly expressed but are recoverable. The property is shared with English VPE and the phenomenon is considered to be VPE. I argued that No- $d a$ Focus Construction is the underlying construction of Japanese VPE. I also argued that Japanese VPE undergoes focus movement: focused elements can move up to Spec of FocP in the structure of the left periphery and the remnant can be deleted. I claimed that items that can determine the negation of the clause, such as, -mo 'also' and zenzen '(not) 
Michiko Todokoro Buchanan

at all' can license Japanese VPE, and that PF-deletion is involved. I also demonstrated how VPs are elided and recovered.

\section{References}

Bresnan, Joan. 1976. On the Form and Functioning of Transformations. Linguistic Inquiry 7:3-40.

Dalrymple, Mary, Stuart M. Shieber, and Fernando C. N. Pereira. 1991. Ellipsis and Higher-order Unification. Linguistics and Philosophy 14:399-452.

Fiengo, Robert and Robert May. 1994. Indices and Identity. Cambridge, Massachusetts: MIT Press.

Fox, Danny. 2000. Economy and Semantic Interpretation. Cambridge, Massachusetts: MIT Press.

Hankamer, Jorge and Ivan Sag. 1976. Deep and Surface Anaphora. Linguistic Inquiry 7:391-426.

Hardt, Daniel. 1999. Dynamic Interpretation of Verb Phrase Ellipsis. Linguistics and Philosophy 22: 187-221.

Hiraiwa, Ken and Shinichiro Ishihara. 2002. Missing Links: Cleft, Sluicing, and "No da" Construction in Japanese. MIT WP in Linguistics 43:35-54.

Hoji, Hajime. 1998. Null Object and Sloppy Identity in Japanese. Linguistic Inquiry 29:127-152.

Israel, Michael. 2001. Minimizers, Maximizers and the Rhetoric of Scalar Reasoning. Journal of Semantics 18:297-331.

Kim, Jeong-Seok and Keun-Won Sohn. 1998. Focusing Effects in Korean/Japanese Ellipsis. Japanese/Korean Linguistics 8:459-470.

Kuno, Susumu. 1973. The Structure of the Japanese Language. Cambridge, Massachusetts: MIT Press.

Lobeck, Anne. 1995. Ellipsis: Functional Heads, Licensing and Identification. Oxford: Oxford University Press.

Oku, Satoshi. 1998. LF Copy Analysis of Japanese Null Arguments. Chicago Linguistic Society 34:299-314.

Otani, Kazuyo and John Whitman. 1991. V-raising and VP-ellipsis. Linguistic Inquiry 22:345-358.

Potsdam, Eric. 1997. NegP and Subjunctive Complements in English. Linguistic Inquiry 28:533-540.

Rizzi, Luigi. 1997. The Fine Structure of the Left Periphery. In L. Haegeman, ed., Elements of Grammar: Handbook in Generative Syntax, 281-337. Dordrecht: Kluwer Academic Publishers.

Rooth, Mats. 1992. Ellipsis Redundancy and Reduction Redundancy. In S. Berman and A. Hestvik, eds., Proceedings of the Stuttgart Ellipsis Workshop, 1-26. Stuttgart: Universities of Stuttgart and Tübingen, and IBM Germany.

Sag, Ivan. 1976. Deletion and Logical Form. Ph.D. diss., MIT. 
Tancredi, Christopher. 1992. Deletion, Deaccenting, and Presupposition. Ph.D. diss., MIT.

Tomioka, Satoshi. 1998. The Laziest Pronouns. Japanese/Korean Linguistics 7:515-531.

Williams, Edwin S. 1977. Discourse and Logical Form. Linguistic Inquiry 8:101139.

Michiko Todokoro Buchanan

University of Minnesota

Linguistics

214 Nolte Center

315 Pillsbury Drive S.E.

Minneapolis, MN 55455

buch0119@umn.edu 